\title{
Study on Strategy of Automatic Shift Based on ANFIS for Intelligent Pure Electric Vehicle
}

\author{
Bingli Zhang, Jiaoyu Xing*, Yunsheng Ye and Zhihao Bai \\ School of Automobile and Traffic Engineering, Hefei University of Technology, Hefei 230009, China \\ ${ }^{*}$ Corresponding author
}

\begin{abstract}
In intelligent pure electric vehicle, different shift strategies has a great influence in energy consumption, The paper established the ANFIS shifting strategy based on the fuzzy neural network control theory and the traditional two parameters shift rules, training the ANFIS shifting strategy by the Sample data, and then built the vehicle model in the Cruise as a simulation environment, and substituting the parameters of the simulation, obtained the simulation results, then compared with the single fuzzy shift strategy, the results show that ANFIS shift strategy can effectively improve the efficiency of the vehicle, and the energy consumption has been optimized in the energy.
\end{abstract}

Keywords-fuzzy system; ANFIS; shifting strategy; intelligent pure electric vehicle; vehicle simulation

\section{I.INTRODUCTION}

Traditional automatic shift strategy is divided into single parameter (speed), two parameters (speed, throttle opening), three parameters (speed, throttle opening, acceleration) shift rules. Two parameters shift strategy is relatively mature, and it is established on the model which the controlled object is accurate. With the development of the theory of intelligent control, more intelligent control technologies are used in vehicles. And the fuzzy control and neural network control have gradually been applied to the automatic shift control strategy. The fuzzy shift control system in the ramp shift process is established by Lv Huanhuan at JiLin University[1], based on fuzzy control theory, and they simulate it. The vehicle shift fuzzy controller which can reflect the intention of the driver is designed by $\mathrm{Ge}$ Jiangchen at JiLin University[2], using fuzzy logic control theory and considering the nonlinear characteristic of the vehicle automatic shift system. The shift model is established by $\mathrm{Li}$ Xiulan[3], based on multi-scale wavelet neural network and they verify it in the experiment. Neural network has strong nonlinear mapping ability and generalization ability, and can be trained dynamically to adapt to changes in the car conditions, road conditions and driver characteristics. Fuzzy system and neural network is combined in fuzzy neural network (ANFIS). ANFIS has the ability of learning, recognizing and adapting and work better when dealing with large-scale fuzzy application problems. Thus, this paper puts forward a automatic shift strategy based on ANFIS, and makes the simulation experiments in the CRUISE vehicle model. Then this paper compares it with fuzzy shift strategy to verify the rationality and superiority.

\section{A FuZZY NEURAL NETWORK SHIFT STRATEGY}

In fuzzy neural network, the input and output signals of fuzzy system is represented by the neural network's input and output node. Membership function and fuzzy rules is represented by the implied (middle) node of the neural network. Fuzzy neural network system realize self-learning and adaptive functions of fuzzy system by using the method of neural network, adjusting the design parameters of the fuzzy system on the basis of designing automatically by the input and output of learning samples.

\section{A. Input and Output Variables and the Membership Functions}

In this paper, the two parameters shift strategy is set as the main research target. And the speed and throttle opening is put as input. And the gear is put as output. This paper uses the two input and single output of first-order Sugeno fuzzy inference system[4], the form of fuzzy rules as follows:

$$
\text { 3.....n) }
$$$$
\text { if } \mathrm{x}_{1} \text { is } \mathrm{A}_{1}{ }^{\mathrm{i}} \text { and } \mathrm{x}_{2} \text { is } \mathrm{A}_{2}{ }^{\mathrm{i}} \text {, then } \mathrm{u}_{\mathrm{i}}=\mathrm{p}_{\mathrm{i}} \mathrm{x}_{1}+\mathrm{q}_{\mathrm{i}} \mathrm{x}_{2}+\mathrm{r}_{\mathrm{i}}(\mathrm{i}=1,2 \text {, }
$$

When $\mathrm{x}_{\mathrm{i}}$ activate $\mathrm{m}$ fuzzy rule, output conclusion will be decided by the output $\mathrm{u}_{\mathrm{i}}$ of the $\mathrm{m}$ rule.

Fuzzy neural network system (ANFIS) based on the Sugeno type fuzzy inference can make the fuzzy system simulate the input and output relationship ideally, learning the known data of the study and training it.

According to the traffic state parameters and the good driver's experience, this paper selects the vehicle's speed and throttle opening as input of ANFIS shift strategy and gear as output.[5-7]

According to the need of Sugeno fuzzy inference system established in this paper, the chosen fuzzy set of the input variable speed and the throttle opening are:

Speed: \{VS(very small), S(small), M(middle), B(big), VB(very big)\}

Throttle opening: \{VS(very small), S(small),M(middle),B(big),VB(very big)\}

Quantifying the speed and the throttle opening, the selection of each variable universe is respectively:

Speed:

$\{0,1,2,3,4,5,6,7,8,9,10,11,12,13,14,15,16,17,18\}$

Throttle opening:

$\{0,0.1,0.2,0.3,0.4,0.5,0.6,0.7,0.8,0.9,1\}$ 
The actual range of the speed:[0 120]

The actual range of the throttle opening:[0 1$]$

According to the variable universe and the actual range of each variable, we can calculate it: the speed quantitative factor $\mathrm{k} 1=0.15$, the throttle opening quantitative factor $\mathrm{k} 2=$ 1.

Taking the membership function of the fuzzy input variables as the gaussian distribution, the membership degree curve of fuzzy subset of the speed and throttle opening are shown in figure 1 , figure 2 .

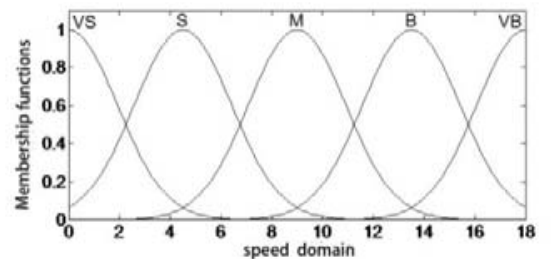

FIGURE I. THE SPEED OF MEMBERSHIP FUNCTIONS

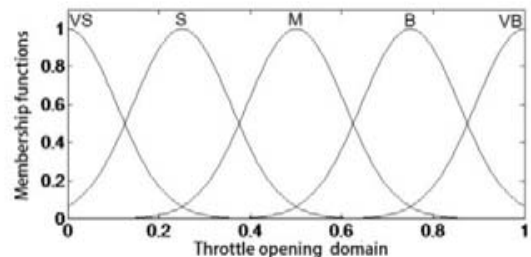

FIGURE II. THE THROTTLE OPENING MEMBERSHIP FUNCTIONS

\section{B. The ANFIS Shifts Rules}

Based on driver's experience and expert knowledge, ANFIS shift rules make the automatic shift control table which is shown in table 1 with reference to the Sugeno fuzzy inference system structure.

TABLE I. SHIFT RULE TABLE

\begin{tabular}{|c|c|c|c|c|c|}
\hline \multirow{2}{*}{$\begin{array}{c}\text { throttle } \\
\text { opening }\end{array}$} & \multicolumn{5}{|c|}{ speed } \\
\hline & VS & $\mathrm{S}$ & $\mathrm{M}$ & $\mathrm{B}$ & VB \\
\hline VS & I & I & I & II & II \\
\hline S & I & I & I & II & III \\
\hline M & I & I & II & III & III \\
\hline B & I & II & II & III & III \\
\hline VB & II & II & III & III & III \\
\hline
\end{tabular}

\section{The Shift Strategy Based on ANFIS}

This paper selects the vehicle's speed and throttle opening as input and gear as output. Then we put the ANFIS shift rules into the simulink to establish the final shift control strategy, as shown in figure 3.

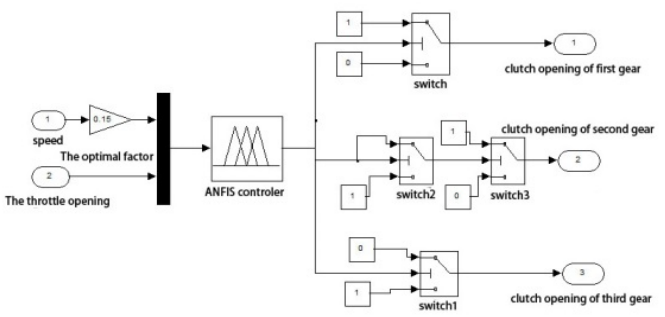

FIGURE III. ANFIS SHIFT STRATEGY MODEL

\section{The Vehicle Simulation AND the Result ANALYSIS}

This paper embeds the ANFIS shift strategy into the vehicle environment, then simulate it to verify its superiority and rationality. We can use Cruise to establish the vehicle model of intelligent pure electric vehicle, then embeds the shift strategy into the vehicle model through the interface of Matlab (DLL). Since there is no corresponding switch gear module in Cruise, we can achieve the purpose of switching gear by using the methods of opening and closing the clutch. The vehicle model is shown in figure 4.[8]

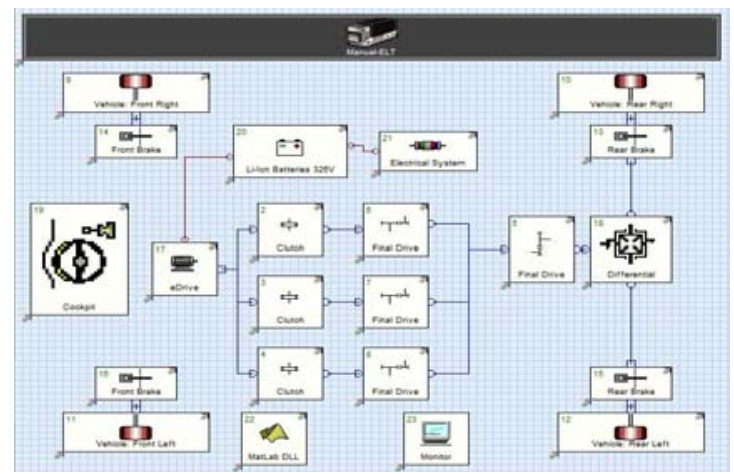

FIGURE IV. INTELLIGENT PURE ELECTRIC VEHICLE VEHICLE MODEl

This paper compares fuzzy shift strategy with ANFIS shift strategy on the condition of the NEDC cycle running condition. intelligent pure electric vehicle parameters are shown in table 2.

TABLE II. PARAMETER LIST PURE INTELLIGENT PURE ELECTRIC
\begin{tabular}{cc}
\multicolumn{2}{c}{ VEHICLE } \\
\hline Designation & number \\
\hline curb weight $/ \mathrm{kg}$ & 891 \\
total mass $/ \mathrm{kg}$ & 1490 \\
total mass $/ \mathrm{mm}$ & 1400 \\
windward area $/ \mathrm{m}^{2}$ & 2.7 \\
Drag coefficient & 0.4 \\
Final drive & 3.5 \\
& 5.0 (first gear) \\
Transmission gear ratio & 3.0 (second gear) \\
\end{tabular}

Entering the main parameters of intelligent pure electric vehicle to the corresponding module of the vehicle model to make a simulation analysis, we can get the vehicle following graph and gear changing graph. 


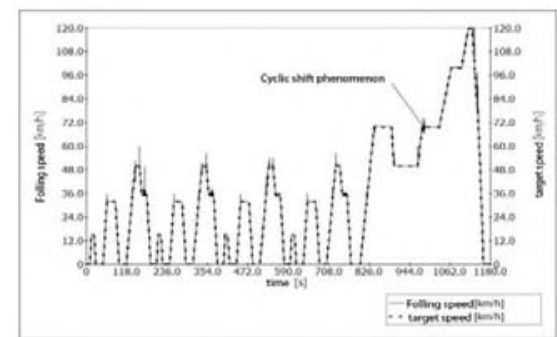

FIGURE V. VEHICLE FOLLOWING CURVE UNDER THE NEDC WORKING CONDITION—FUZZY SHIFT STRATEGY

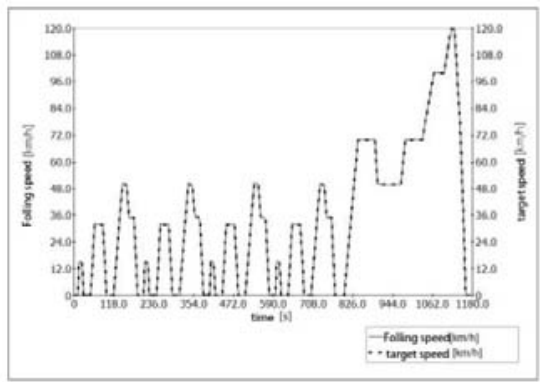

FIGURE VI. VEHICLE FOLLOWING CURVE UNDER THE NEDC WORKING CONDITION—ANFIS SHIFT STRATEGY

Figure 5 and figure 6 are respectively based on the vehicle-following curve of fuzzy shift strategy and that of ANFIS shift strategy. The former is relatively smooth and vehicle can be driven in the speed we set. The latter is in a rush at a certain moment and there is cyclic shift phenomenon in the operation process.

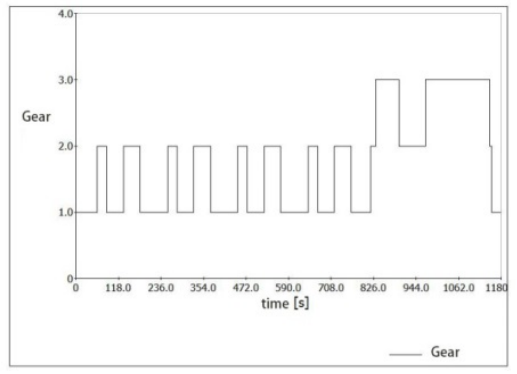

FIGURE VII. GEAR CHANGE UNDER THE NEDC WORKING CONDITION-ANFIS SHIFT STRATEGY

We can know that the gear change is in line with the driver's operation intention from the figure 7 that is the description of the gear change on the condition of the NEDC. And it verifies the rationality of the ANFIS shift strategy.

\section{CONCLUSION}

Based on the traditional two parameters shift strategy, ANFIS shift strategy is established. Then we train it by using the sample data. Later it is compared with fuzzy shift strategy in a vehicle environment. The simulation results show that ANFIS shift strategy can effectively improve the operation stability and economic performance.

\section{ACKNOWLEDGEMENTS}

Fund Projrct: Major projects of science and technology plan projects in anhui province(15czz02039)

Anhui science and technology research project (1604a0902159).

Author's introduction: ZHANG Bingli(1968-), male, Hefei, Anhui, Doctor, professor of Hefei university of technology

XING Jiaoyu(1990-), male, Shuozhou, Shanxi, graduate student of Hefei university of technology, TEL: 15922440690

\section{REFERENCES}

[1] LV Huanhuan. Slope Shift Strategy for Automatic Transmission Based on Fuzzy Rectification [D].Jilin: Jilin University, 2013

[2] [2] GE Jiangcheng. Study on Gear Shift Schedule of Automated Mechanical Transmission in Parallel Hybrid-Electric Vehicle [D].Jilin: Jilin University, 2013

[3] [3] LI Xiulan, QIN Sicheng,YANG Hongtao. Shift Strategy of Construction Vehicle Based on Multi-scale Wavelet Neural Network [J]. Journal of Sichuan University: Engineering science edition, 2013(02):173-176

[4] [4] YAN Zhenping, AI Jianliang. ANFIS application in aircraft stability control system[J]. Journal of Fudan University, 2010,49(4):530-534.

[5] [5] ZHU Dandan. Study on Shift Schedule of Pure Electric Vehicles Automatic Transmission Based on Urban Road Conditions [D].Hefei: Hefei University of Technology, 2012.

[6] [6] YAO Haifeng. Modeling and Simulation of Pure Electric Vehicle Performance [D].Nanjing: Nanjing University of Science and Technology,2011.

[7] [7] ZHANG Bingli, ZHANG Youhuang, ZHAO Han. Simulation of automatic transmission performance based on Simulink and Stateflow[J]. journal of Hefei University of Technology: natural science edition, 2010,33(08):125-130.

[8] [8] QIN Hao. Study on the AMT Shift Strategy for Parallel Hybrid Electric Bus [D].Changchun: Jilin University,2014 